\title{
Improvement and Evaluation of Copper Oxidation Experimental Procedure for the Introduction of the Law of Definite Proportion
}

\author{
Shuichi Yamashita*, Yasuyuki Kashiwaguma, Hideko Hayashi, Verena Pietzner \\ ${ }^{1}$ Faculty of Education, Chiba University, ${ }^{2}$ School of Mathematics and Science, Carl von Ossietzky University \\ *Corresponding Author: syama@faculty.chiba-u.jp
}

\section{ABSTRACT}

In science classes, students usually learn about the law of definite proportions by the oxidation of copper. However, common procedures usually do not lead to proper results. This leads to confusion among the students because their experimental results do not fit to the theoretical values. Therefore, we invented a new procedure for this experiment to improve the introduction of the law of definite proportions. The new procedure can also be done by the students, and it is done within 15 min and provides theoretical data written in the textbook. To evaluate this improved procedure, we let $8^{\text {th }}$ year students $(n=133)$ do the copper oxidation experiment in the traditional and the improved way. The oxidation ratio doing the improved method was $98 \%$, whereas the traditional way was only $55 \%$. Students' individual feedback indicates that the new method might be able to improve the understanding of the law of definite proportions.

KEY WORDS: copper oxidation experiment; law of definite proportions; improvement; evaluation

\section{INTRODUCTION}

T

The law of definite proportions is an important learning objective; it explains the constant mass ratio of the compounds reacting in a chemical reaction. Based on this law, the constant atomic ratios within chemical reactions can be derived. Since understanding this law is crucial for understanding the principles of chemical reactions, it is an important topic for the students to learn. Therefore, it is of great importance that the relating experiment for teaching this law leads to good results. In Japan, the law of definite proportions is taught with the help of the oxidation of copper with oxygen from the air. For this, the weight of a copper powder is measured; afterward, it is heated, and the mass of the obtained copper oxide is compared with the mass of the copper before the reaction started. Based on the calculation, $2.0 \mathrm{~g}$ of copper oxide should be obtained from $1.6 \mathrm{~g}$ of copper that reacts completely with oxygen. However, Matsunaga and Ikeda (2012) reported that the average mass of copper oxide that is normally produced is between $1.82 \mathrm{~g}$ and $1.87 \mathrm{~g}$ when students perform the experiment, which is lower than the theoretical value $(2.0 \mathrm{~g})$. There is a significant difference between the theoretical and measured values of the mass of copper oxide. In fact, the correct mass ratio of the oxygen combined with the copper could not be derived using the experimental results. One reason for this is that only the surface of the copper is oxidized (Takada, 1996), but also experimental skills of the students as well as laboratory equipment play an important role (Wilhelm, 1973).

For improving the experimental procedure of this experiment, we first compared the procedures described for copper oxidation in five different Japanese junior high school science textbooks from different textbook publishing companies (Figure 1).

The common point between the experimental procedures described in these textbooks is the repeated weighing after heating and cooling of the copper powder. However, there are differences between the five with regard to the intensity of heating, the stirring procedure, the heating time, and the mass of the copper powder that is heated. For the intensity of heat, the differences included (a) applying high heat after applying low heat, (b) high heat, and (c) no explicit specifications. Furthermore, with regard to stirring of the copper powder, stirring was mainly performed after cooling. Regarding the duration of heating, only one textbook specified a time, and the description only stated that students should "stop heating when it turns black" or "stop heating if no further changes can be observed in the powder." When heating the copper powder, the surface becomes black within 1 or $2 \mathrm{~min}$, and no significant changes are observed thereafter. Moreover, since there is no specification regarding the duration of heating, individual variations in the procedure occur. Furthermore, three of the five companies specified that the mass of copper powder used should be $<1.5 \mathrm{~g}$, whereas the other two suggested using $1.5 \mathrm{~g}$ or more. The issues encountered during the copper oxidation experiments may, therefore, be explained by the different experimental methods and reputation used.

In this study, we aimed to improve the copper oxidation experiment to enable students to get reliable results for investigating the law of definite proportions. After optimizing 


\section{2 化合する物質の質量の割合}

実楼了では，公気中でマグネンウムリポンやスチールウ

ールを加闖した。そのをき，マグネシウムや铁（スチール

ウール）酸秦と化合し、生成した固体の宣最は均加した。

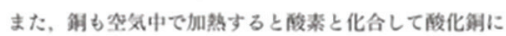

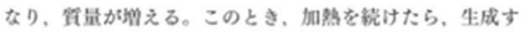

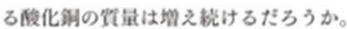

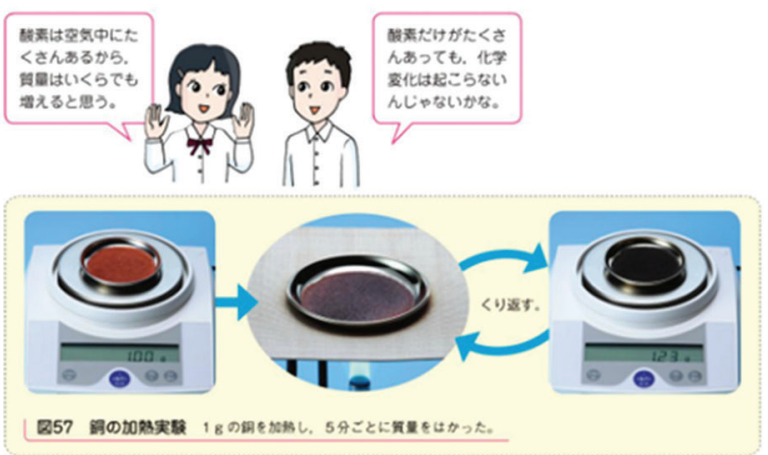

因57の实駼結果をダラフにすると、

四58のように䒘る。このグラフから，

はじめは加熟の同数とともに加照緂の物

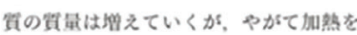

くり返しても変化しなくなるとわかる。

つまり，一证量の䬣と化合吉る淩素の筧

量には, 睤界がある。

では，金属か称素と化合するとき，金 属の筫是と化合する釉秦の賽量の間には， とのよう教關があるのだろうか

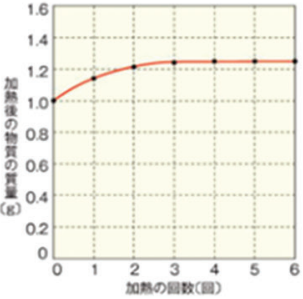

258

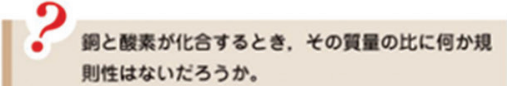

則性はないだろうか。

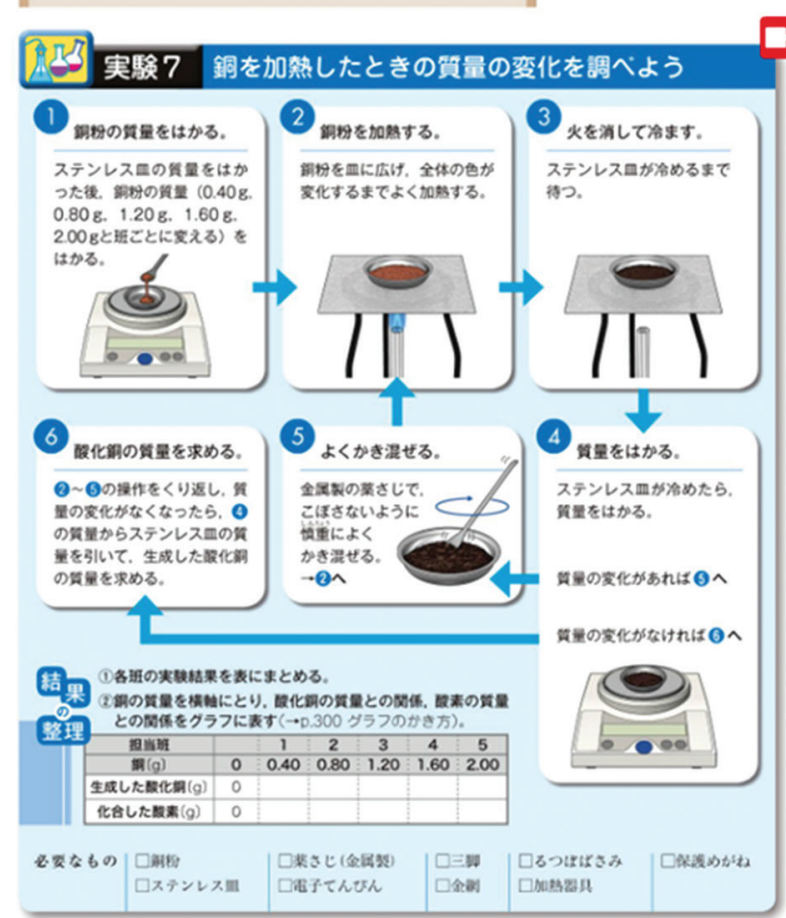

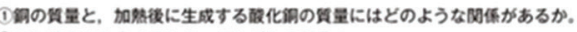

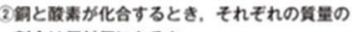

玮合は何対何になるが。

60 -

Figure 1: An example of copper oxidation experiment in Japanese science textbook (Arima et al., 2011)

the experimental procedure, we did an evaluation within science classes.

\section{METHOD}

\section{Improved Copper Oxidation Experimental Method}

As Takada (1996) reported, one main source of the insufficient result is the relatively low surface of normal copper powder. Therefore, we used a very fine copper powder called EL350 copper, which means that the particle size of the copper particles is $<350 \mu \mathrm{m}$. In addition, a lid is placed on a container housing the powder so that a high heating temperature can be maintained and continuous heat is applied. In our improved method, as illustrated in Figure 2, three sides of a container are protected by a wind guard, and using a triangular wire frame and a stainless steel Petri dish, the gas burner is adjusted to intensive heating at the level of "fire power 3." After 5 min of heating, the stainless steel Petri dish is covered and continuously heated further for $10 \mathrm{~min}$, resulting in a total heating time of $15 \mathrm{~min}$, by the gas burner. Following this, the lid that is used is inverted with respect to the heating container, and complete sealing is prevented by winding a wire in a cross shape to facilitate covering (Figure 3). Furthermore, the lid is used in a slightly shifted position. The powder is then cooled for about 3 min on a metal stand, and after the container has

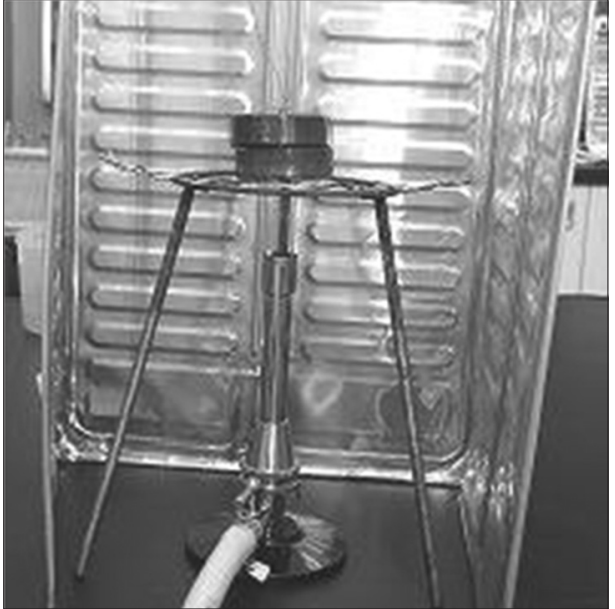

Figure 2: Protected by a wind guard

cooled sufficiently so that it can be touched by hand, the mass is weighed using an electronic balance.

\section{Doing the Experiment in Class}

We conducted practice classes with $8^{\text {th }}$ year students at Chiba University lower secondary school. In June 2014, we asked $8^{\text {th }}$ year students to use the conventional experimental method described in textbooks to collect the data for improvement. In 
February 2016, we asked $8^{\text {th }}$ year students to use the conventional experimental method and our improved method. In June 2014, 150 students in four classes participated, and in February 2016, 113 students in three classes participated in the practice classes.

The experiments were conducted using groups of three or four students, and there were 10 groups in each class. The mass of the copper used in the experiments was set to $0.4,0.8$, $1.2,1.6$, and $2.0 \mathrm{~g}$, and each group performed the experiment using a specific mass of copper. After this, based on the mass measured by each group, a graph was prepared for each class showing the mass of the copper powder and that of the combined oxygen for the entire class. The mass was measured using an electronic balance (Mettler, PL 602 E). Following the conventional experimental method described by the textbooks, repeated heating was performed, which indicated that the masses of copper and oxygen are proportional, and the copper-to-oxygen mass ratio is $4: 1$. During the experiments conducted in February 2016 using the improved procedure, we additionally provided guidance on how the mass could be accurately measured using the electronic balances, how the flame of the gas burner could be adjusted to level "fire power 3 ," and how to ensure that the heating time is $15 \mathrm{~min}$. In the classrooms, city gas was used. The height of the gas burner was $16.5 \mathrm{~cm}$ and that of the tripod was $20 \mathrm{~cm}$; the distance of the tip of the gas burner to the tripod was $3.5 \mathrm{~cm}$. Heating conditions were similar to those that were applied when using liquid propane gas. Since the temperature was not measured, the heating temperature may have varied in the students' experiments. After the experiments using the conventional and improved method were completed, we conducted a survey on the following items with a five-point Likert scale questionnaire (1: Disagree, 2: Slightly disagree, 3: Neither, 4: Slightly agree, and 5: Agree) as follows:

1. I was able to measure the mass accurately.

2. I was able to perform the experiment safely and carefully.

3. Based on the results of this experiment, a mass ratio of copper-to-oxygen of 4:1 was achieved.

4. The experimental method was difficult.

Furthermore, the participants were invited to voluntarily describe the difficulties they encountered and their general experience about the experiments.

\section{RESULTS}

\section{Evaluation of the Improved Experimental Method}

After excluding the groups that performed the experimental operations inadequately (such as spilling the copper powder during the experiment), the results for 38 of the 40 groups in the four classes in 2014 and 28 of the 30 groups in the three classes in 2016 were evaluated based on the mass of the combined oxygen. The mass of the oxygen relative to 0.4-2.0 $\mathrm{g}$ of copper is shown in Figure 4. In the conventional experimental method, the heating temperature and heating time differed depending on the faculty members and groups that performed the experiments. The oxidation rate in both
2014 and 2016 was between $55 \%$ and $60 \%$ for every class. From this result, when expressing the proportion of the mass of oxygen combined with copper, a ratio of copper-to-oxygen of about 7.5:1 was obtained; this was significantly different from the theoretical value of $4: 1$. However, when the improved experimental method was used, the result (Figure 4 improved) was much closer to that of the theoretical value.

We then compared the oxidation rates for each mass of the copper used (Figure 5). In the conventional experimental method, when the mass of the copper was $0.4 \mathrm{~g}$, the oxidation rate exceeded $70 \%$, and depending on the experimental group, an oxidation rate of $100 \%$ was attained. However, when the mass of the copper was $0.8-2.0 \mathrm{~g}$, an oxidation rate of $44-71 \%$ was obtained, and the oxidation rate tended to decrease as the mass of the copper increased. When the improved experimental method was used, the oxidation rate was $98 \%$ even for $2.0 \mathrm{~g}$ of copper, and it was possible to reduce the decrease in oxidation rate in the presence of larger masses of copper.

\section{Evaluation Using the Questionnaires}

Of the 113 participants in the February 2016 classes, we used data of the 100 that did both the conventional and improved

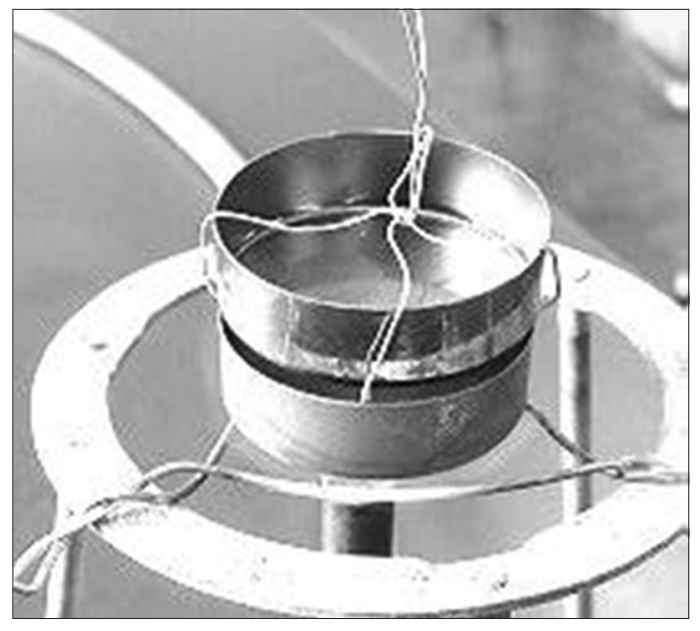

Figure 3: Covered stainless steel Petri dish

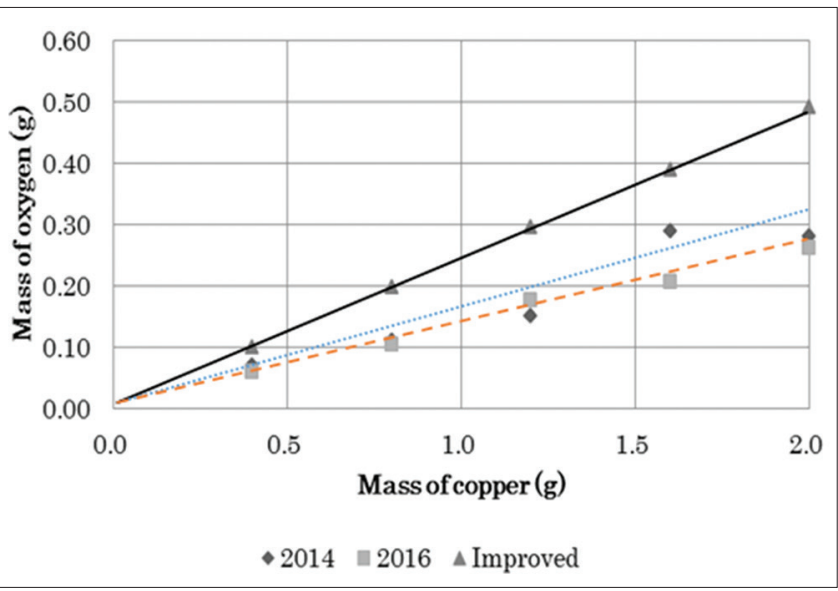

Figure 4: Mass of the oxygen relative to copper 


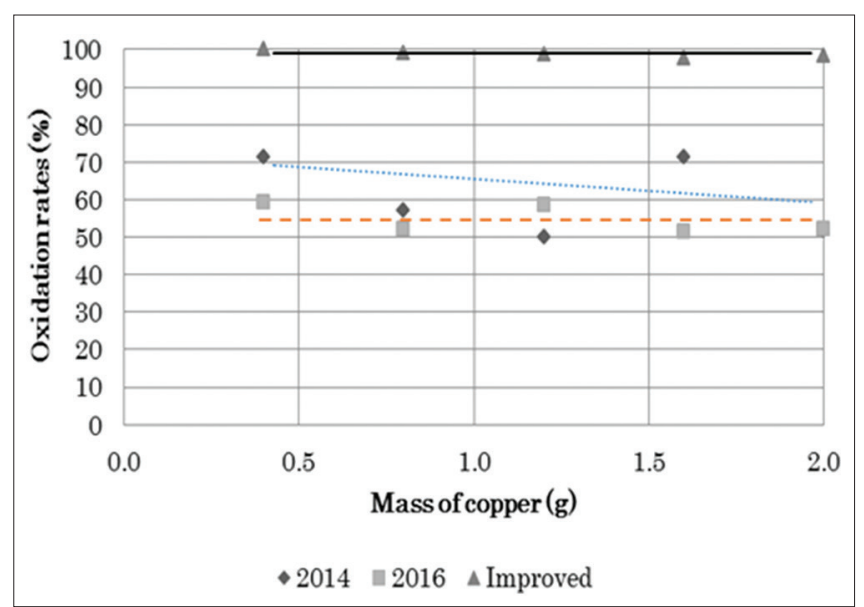

Figure 5: Oxidation rates for each mass of copper

\begin{tabular}{lccc}
\hline Table 1: Average score of questionnaire & \\
\hline Question topic & \multicolumn{2}{c}{ Average (SD) } & t-value \\
\cline { 2 - 3 } & $\begin{array}{c}\text { Conventional } \\
\text { method }\end{array}$ & $\begin{array}{c}\text { Improved } \\
\text { method }\end{array}$ \\
\hline Accuracy & $3.97(1.31)$ & $4.57(0.81)$ & $4.33^{* *}$ \\
Safety & $4.60(0.95)$ & $4.89(0.42)$ & $3.03^{* *}$ \\
Mass ratio (4:1) & $2.02(1.22)$ & $4.86(0.38)$ & $21.49^{* *}$ \\
Difficulty & $3.28(1.05)$ & $3.28(1.08)$ & 0.00 \\
\hline
\end{tabular}

$* * \rho<0.01$, SD: Standard deviation

\begin{tabular}{lcc}
\hline \multicolumn{3}{l}{ Table 2: Number of students faced difficulties } \\
\hline Difficulty & Conventional method & Improved method \\
\hline Spilling & 20 & 2 \\
Heating & 3 & 3 \\
Timing & 10 & 7 \\
Operation & 0 & 7 \\
\hline
\end{tabular}

experimental methods and answered all of the questions in the survey. We scored the answers to question items (1-4) with a full score of 5 and compared the answers for the conventional method with our improved one. Table 1 summarizes the average score, standard deviation (SD), and t-test results for each survey. Question (1) seems to highlight a significant difference in terms of the ability of participants to accurately measure the mass and ensure that the experimental results are close to the theoretical value as it became possible to measure accurately the mass. Question (2) reflected the significant differences in the participants' capability to conduct the experiments safely. For question (3), significant differences were found regarding the mass ratio of copper-to-oxygen, and the average score also increased significantly from 2.02 to 4.86. After conducting the experiment using the conventional experimental method, answers of "agree" or "slightly agree" about whether a mass ratio of 4:1 was achieved for copperto-oxygen were given by $12 \%$ of the respondents, whereas "disagree" or "slightly disagree" were given by $71 \%$. In contrast, after the improved experiment, the proportion of positive answers (i.e. "agree" or "slightly agree") was $99 \%$, of which $88 \%$ responded "agree." Notably, for most of the participants who answered "slightly agree," their results were not quite the same as that of the theoretical value. It can, therefore, be inferred that this high approval rating was because of the impact of the students' own results rather than those of the entire class. There was no significant difference regarding the difficulty of the improved method according to the answers for question (4). Although we required the participants to use advanced skills for their age group, such as mass measurements and heating at temperatures above those used in the conventional experimental method, the level of difficulty was observed to be the same; as such, it is feasible for students to use our improved method in the class.

Table 2 summarizes the voluntary descriptions given by participants about the difficulties that they faced during the experiments. Regarding mass, because stirring was not employed, spilling was less frequent. Furthermore, because a set heating time was used, it became unnecessary to judge whether oxidation had occurred by noting the color change. However, more participants felt that the improved procedure was time consuming, even after receiving instructions on the mass, amount of heat and time, seven participants still believed it was too difficult due to the detailed operations required. Meanwhile, for the experimental method, seven participants answered that "if proceeding properly, it is possible to do the method accurately," "it is important to do it carefully," and "the time and other conditions were easy to understand," whereas seven other participants answered that "it was easy." Individual differences were observed regarding the adjustment of the mass, amount of heat, and time. In addition, with regard to the improved method, 43 participants expressed sentiments such as " $i$ was impressed by attaining the theoretical value" and "it was amazing to be able to obtain the correct value."

\section{DISCUSSIONS AND CONCLUSIONS}

By conducting copper oxidation experiments using an improved method utilizing continuous heating of a copper powder under a lid, it was possible for a high value of $98 \%$ to be obtained for the mass of oxygen with respect to the theoretical value. From our results, we determined that $99 \%$ of students who participated in our study were able to confirm that the law of definite proportions could be derived for the mass ratio of copper-to-oxygen (namely, 4:1).

To obtain the results of the copper oxidation experiments that were close to the theoretical value, mass was measured to a precision of $0.01 \mathrm{~g}$, and heating was performed using a gas burner. Therefore, an electronic balance has to be used for our improved method, and instructions should be given to students about performing mass measurements; furthermore, they should be able to use a gas burner that is operating at high temperatures. Finally, these results were mainly obtained by comparing two kinds of copper powders; it would be desirable 
to examine whether similar results could be obtained for other kinds of copper powder. In addition, other experiments that are suitable to teach the law of definite proportions should be identified and implemented in class; this will be part of the following study.

\section{ACKNOWLEDGMENTS}

Part of this research was supported by Japan Society for Promotion of Science (JSPS) through grants-in-aid for scientific research (KAKENHI). Grant number 15H02910

\section{REFERENCES}

Arima, A., Hirakawa, Y., Arima, H., Wang, X., Chalmers, J., \& Wang, J. (2011). Science World 2. Tokyo: Dainippon Tosho. pp. 60-61

Matsunaga, T., \& Ikeda, Y. (2012). Theory-dependent practical study of science (1) "Copper Oxidation" in junior high school science education, Bulletin of Research Centre for Educational Practice, Faculty of Education, Yamaguchi University, 33, 143-152.

Takada, H. (1996). Metal oxide problems in junior high school science classes and related challenges. Chemistry and Education, 44(3), 158-161.

Wilhelm, D.L. (1973). The law of definite proportions. An experiment for introductory chemistry. Journal of Chemical Education, 50(6), 436-437. 